\title{
A ESTRUTURAÇÃO DO MERCADO PUBLICITÁRIO DE SÃO JOSÉ DOS CAMPOS E TAUBATÉ - SP A PARTIR DA INSTALAÇÃO DAS TVS ABERTAS REGIONAIS ${ }^{1}$
}

\author{
The São José dos Campos and Taubaté - SP advertising market structuration \\ from the installation of regional open TVS
}

\section{La estructura del mercado publicitario de São José dos Campos y Taubaté - SP de la instalación de TVS abiertas regionales}

Giselle da Cunha Estefano Toledo Mestre em Gestão e Desenvolvimento Regional - Universidade de Taubaté gtoledo@band.com.br

Monica Franchi Carniello Doutora em Comunicação e Semiótica (PUCSP)

Docente do Mestrado em Gestão e Desenvolvimento Regional da Universidade de Taubaté - SP monicafcarniello@gmail.com

\section{Resumo}

O mercado publicitário brasileiro passa por um processo de regionalização e interiorização, que ganha evidência a partir da década de 1990. O objetivo geral do artigo foi caracterizar o mercado publicitário do Vale do Paraíba - SP a partir da implantação da televisão aberta regional em São José dos Campos e em Taubaté. A pesquisa caracteriza-se como exploratório-descritiva, de abordagem qualitativa, com coleta de dados por meio de entrevista semiestruturada. A amostra foi selecionada pelo critério de julgamento, focando nos atores sociais participantes do processo de implantação das televisões regionais no Vale do Paraíba SP. Verificou-se que houve uma estruturação e profissionalização do mercado publicitário regional a partir da chegada da televisão regional aberta, fomentando toda a cadeia produtiva da comunicação.

Palavras-chave: Televisão regional. Mercado publicitário. Regionalização.

\begin{abstract}
The Brazilian advertising market goes through a process of regionalization and interiorization, gaining evidence from the 1990s. This article aims to characterize the advertising market of

\footnotetext{
${ }^{1}$ Uma versão do texto com resultados parciais da pesquisa foi apresentada no $8^{\circ}$ Encontro Nacional de História da Mídia, Guarapuava, PR, em 2011 e publicada como capítulo do livro Histórias da mídia : campos da publicidade e da comunicação institucional. 1ed.Santa Maria: Facom Santa Maria, 2013, organizado por Ana Luiza Coiro Moraes, Flavi Ferreira Lisbôa Filho, Marília de Araujo Barcellos.
} 
the Vale do Paraíba - SP from the implementation of regional broadcast television in São José dos Campos and Taubaté. The research is characterized as exploratory, descriptive, with qualitative approach and data collection through semi-structured interviews. The sample was selected by the judging criteria, focusing on social actors that participated in the process of implementation of regional television stations in the Vale do Paraíba - SP. It was found that it happened a structuration and professionalization of the regional advertising market from the arrival of regional television, encouraging the entire production chain of communication.

Key words: Regional television. Advertising market. Regionalization.

\section{Resumen}

El mercado publicitario brasileño pasa por un proceso de regionalización y la interiorización, ganando las pruebas de los años 1990. El objetivo general del trabajo fue caracterizar el mercado de la publicidad del Valle del Paraíba - SP desde el despliegue de la televisión regional en São José dos Campos y Taubaté. La investigación se caracteriza como exploratorio, el enfoque descriptivo, cualitativo para la recolección de datos a través de entrevistas semi-estructuradas. La muestra fue seleccionada por los criterios de evaluación, centrado en los actores sociales que participan en el proceso de implantación de estaciones de televisión regionales en el Valle del Paraíba - SP. Se encontró que había una estructura y profesionalización del mercado de la publicidad regional desde la llegada de la televisión abierta regional, alentando a toda la cadena productiva de la comunicación.

Palabras clave: La televisión regional. Mercado de la publicidad. Regionalización.

\section{INTRODUÇÃO}

No Brasil, o desenvolvimento e estruturação dos mercados publicitários regionais ganha novos contornos com a chegada a televisão aberta, por conta de sua representatividade na atividade publicitária. No caso do Vale do Paraíba, interior do Estado de São Paulo, as emissoras de televisão se estabeleceram nas cidades de São José dos Campos e de Taubaté, nas décadas de 1980 e de 1990, por meio de concessões públicas, atuando com a área de cobertura que compreende Vale do Paraíba, Serra da Mantiqueira e Litoral Norte.

Parte-se do pressuposto de que a comunicação é um dos elementos que viabiliza o desenvolvimento de uma região e que sua configuração reflete o estágio de maturidade do mercado e dos processos políticos e sociais. Schram (1979, p. 129) foi pioneiro ao estabelecer relações entre comunicação e desenvolvimento, ao afirmar que "[...] quando uma sociedade começa a se modernizar, um dos primeiros sinais de desenvolvimento é a dilatação dos canais de comunicação". Nesse sentido, percebe-se uma estreita relação entre o desenvolvimento de uma região e o acesso à informação.

A televisão oferece, ao telespectador, informações dos mais diversos níveis, e contribui para o processo de escolhas dos indivíduos, ampliando suas possibilidades. Sabe-se 
PROGRAMA DE PÓS-GRADUAÇÃO EM COMUNICAÇÃO DA UNIVERSIDADE FEDERAL DE SANTA MARIA

que, de forma geral, as informações jornalísticas, publicitárias e de entretenimento têm grande influência nas comunidades, muitas vezes conduzindo a sociedade a modismos e fomentando o senso comum. Fato é que a TV possibilita dinamismo e maior acesso às informações do cotidiano, permitindo que as informações veiculadas se tornem assunto de debate público.

Além do acesso à informação, premissa de uma sociedade democrática, condição essencial para o desenvolvimento (SEN, 2000), a comunicação se constitui como uma atividade econômica representativa que participa da geração de emprego e renda de uma região, bem como seu estágio de maturidade se caracteriza como um fator de atratividade de investimentos de empresas de vários setores da economia.

Por essa estreita relação entre comunicação e desenvolvimento regional, torna-se pertinente compreender o processo de formação do mercado publicitário no Vale do Paraíba SP. Apesar de haver emissoras de rádios atuando na região há mais de 70 anos, bem como veículos impressos, jornais e revistas, fato é que, com a chegada da televisão aberta regional, verifica-se uma nítida mudança no processo da atividade publicitária.

Assim sendo, este estudo está focado na constituição do mercado publicitário na região valeparaibana a partir das mudanças que a televisão aberta trouxe para a configuração do mercado de comunicação da região, constituído por agências de propaganda, agências de eventos, assessorias de marketing, imprensa e produtoras de áudio e vídeo, que se formaram após as primeiras concessões de TV nesse âmbito regional.

Todos esses steakholders são parte do processo da comunicação que tem por objetivo atender às necessidades das empresas que atuam tanto no varejo como na indústria de pequeno, médio e de grande porte, buscando informar, divulgar e comunicar seus serviços e produtos, bem como estabelecer uma relação entre a comunidade local e suas marcas, seus produtos, seus serviços e suas ações.

No mercado da comunicação mercadológica, os veículos de comunicação possuem grande relevância na sistematização dos processos e dos fluxos da atividade. No Brasil, constituem-se geralmente em empresas pertencentes a grandes grupos (DONOS DA MÍDIA, 2011).

As emissoras de TV, pelo alcance e pela penetração do meio junto à população, representam 63\% do investimento publicitário nacional (PROJETO INTERMEIOS, 2010). E sob certo aspecto, carregam a tarefa de normalizar o mercado publicitário. As introduções das regras estabelecidas pelo meio levaram o mercado publicitário informal e empírico para um passo rumo a uma formatação estruturada e organizada. 
PROGRAMA DE PÓS-GRADUAÇÃO EM COMUNICAÇÃO DA UNIVERSIDADE FEDERAL DE SANTA MARIA

O objetivo geral desse artigo é caracterizar o mercado publicitário a partir da implantação da televisão aberta regional em São José dos Campos e em Taubaté.

\section{DESENVOLVIMENTO}

\subsection{Regionalização dos mercados publicitários}

O mercado publicitário consolidou-se definitivamente no Brasil na segunda metade do século XX, a partir de variáveis históricas, tais como a institucionalização da profissão, por meio da abertura dos cursos superiores da área de comunicação; a relevância que o veículo rádio adquiriu na sociedade no período indicado; o desenvolvimento tecnológico das mídias, que ampliou as possibilidades de distribuição das mensagens publicitárias em escala massiva; a conformação do conceito e das práticas de marketing, que passaram a compor, ainda que gradativamente, a gestão estratégica das empresas.

Consolidava-se, cada vez mais, a institucionalização da propaganda, como negócio e como profissão, com o surgimento de novos organismos e de novos eventos institucionais. Desde 1959 existia a Associação Brasileira de Anunciantes, para completar o tripé básico: anunciantes, agências, veículos (ANGELO, 1990, p. 28).

Em um primeiro momento, o movimento de estruturação da atividade publicitária ocorreu de forma mais evidente nas capitais, por elas concentrarem o maior volume de empresas e população consumidora potencial. Rio de Janeiro e São Paulo sediaram as primeiras agências. "No fim da década de 30, a revista Propaganda estimava em 56 o número de agências em funcionamento no Rio e em São Paulo" (REIS, 1990, p. 334). Posteriormente, agências foram abertas nas capitais das outras regiões do país.

No entanto, em consonância com um processo de interiorização ocorrido no Brasil, fruto do processo de urbanização intensificado a partir da década de 1970, os mercados publicitários regionais passaram a ganhar maior relevância, o que os levou a uma maior estruturação. Com a industrialização extrapolando os limites das capitais, as cidades do interior adquiriram maior dinamismo e autonomia, ao abrigar as indústrias e toda a cadeia produtiva que se desenvolve a partir do processo de industrialização, fomentando, dessa forma, os mercados publicitários regionais.

Compreende-se por mercado "um conjunto de clientes com renda disponível e uma necessidade específica a ser atendida por uma empresa" (LIMEIRA, 2007, p. 3), situação que ocorre nas cidades de médio porte do interior e que, consequentemente, atrai o interesse dos grandes grupos de comunicação em investirem nas afiliadas regionais, abrindo possibilidades 
antes inexistentes para os mercados publicitários das respectivas regiões. Considera-se a definição de mercado regional

Quando os agentes econômicos e/ou grupos de consumidores potenciais estão concentrados em determinada área geográfica, temos o que se denomina mercado regional. Pela geração de emprego e renda oriundas das trocas de bens e serviços, é usual a aplicação do termo mercado regional para referir-se ao índice de empregos e aos segmentos da economia mais relevantes de uma região. Para definir o mercado regional quando nos referimos ao consumo de mídias, considera-se a área geográfica de cobertura dos veículos de comunicação. Utiliza-se também o termo mercado regional para definir a organização do mercado, ou seja, o conjunto de fornecedores, práticas adotadas, formas de comercialização e particularidades da região abordada (CARNIELLO, 2010, p. 809).

Compreender a estruturação do mercado publicitário é um aspecto importante para compreender o desenvolvimento regional. Carniello (2010, p. 975) destaca as especificidades da propaganda regional.

A propaganda regional caracteriza-se como vertente da comunicação mercadológica que possui público-alvo concentrado em determinada área geográfica, e, portanto veiculação regionalizada, o que lhe atribui algumas particularidades. Quanto à finalidade, não se diferencia da propaganda convencional, que tem por objetivo difundir idéias, produtos ou serviços [...]. Quanto à abrangência, por contemplar os objetivos de anunciantes locais, possui veiculação em uma área restrita, recorrendo aos jornais locais, mídia exterior, afiliadas das redes de televisão e emissoras de rádio. [...] Quanto à forma, a propaganda regional veiculada nos sistemas de mídia está sujeita ao uso dos formatos padronizados e pré-determinados pelos veículos de comunicação, que pouco se diferenciam entre os veículos nacionais e mesmo globais. No entanto, verifica-se a existência de formatos alternativos aos estabelecidos pela grande mídia, como uma maneira de fomentar o desenvolvimento do comércio de uma localidade ou região que não possui recursos financeiros para anunciar nos veículos da mídia regional. [...]. Quanto ao conteúdo, as mensagens da propaganda regional podem explorar características endógenas da região de abrangência da campanha. Se diferencia das campanhas globais ou nacionais que, ainda que fazendo adaptações em função das características das regiões, possuem uma diretriz única. [...] A propaganda regional permite a adequação do conteúdo às características culturais do público-alvo com mais coerência, pois, por ter um escopo menor, tende a ter menos heterogeneidade entre os receptores ou, no mínimo, ter alguns elementos de identificação mais evidentes entre eles (CARNIELLO, 2010, p. 975).

A relação entre comunicação e desenvolvimento regional foi amplamente discutida por Melo (2006, p. 27), que avalia a delimitação dos mercados a partir de um conceito midiático de região, afirmando que, "por mais que tenhamos concentrado o foco da análise nas peculiaridades comunicacionais, nunca deixamos de considerar sua complexidade orgânica, resultante de injunções de ordem política, cultural ou econômica". 
A ideia de categorizar as regiões, segundo o autor, busca produzir conhecimento midiático regionalmente identificado, "sem perder de perspectiva o território nacional a partir do qual está referenciado e o espaço global em cuja órbita pode estar circulando" (MELO, 2006, p. 17).

Peruzzo (2003, p. 12) explica, também, que o regional ainda é pouco explorado, mas a comunicação caminha na direção da regionalização como alternativa de conteúdos segmentados e com uma relação de custo-benefício apropriada aos negócios regionais:

Descobriu-se o local/regional como nicho de mercado, um segmento com potencial de rentabilidade alta e ainda pouco explorado comercialmente. A crise financeira vivida pela mídia contribuiu para empurrar empresas de comunicação em direção da segmentação de mercado, forçando abrirem-se mais a regionalização da produção, em detrimento da estratégia anterior na qual a produção de conteúdos era basicamente centralizada nos grandes centros urbanos como as capitais de São Paulo e do Rio de Janeiro, e distribuída por todo o território nacional.

Para analisar o conglomerado de televisões regionais do mercado do Vale do Paraíba, é necessário contextualizar a sua participação no bolo publicitário do interior de São Paulo e do país.

Verifica-se, no Gráfico 1, o investimento dos anunciantes nas televisões regionais do Vale do Paraíba. Como fonte, foram utilizados os dados do relatório fornecido pelo do IBOPE, referentes ao período que vai de 2003 até 2011.

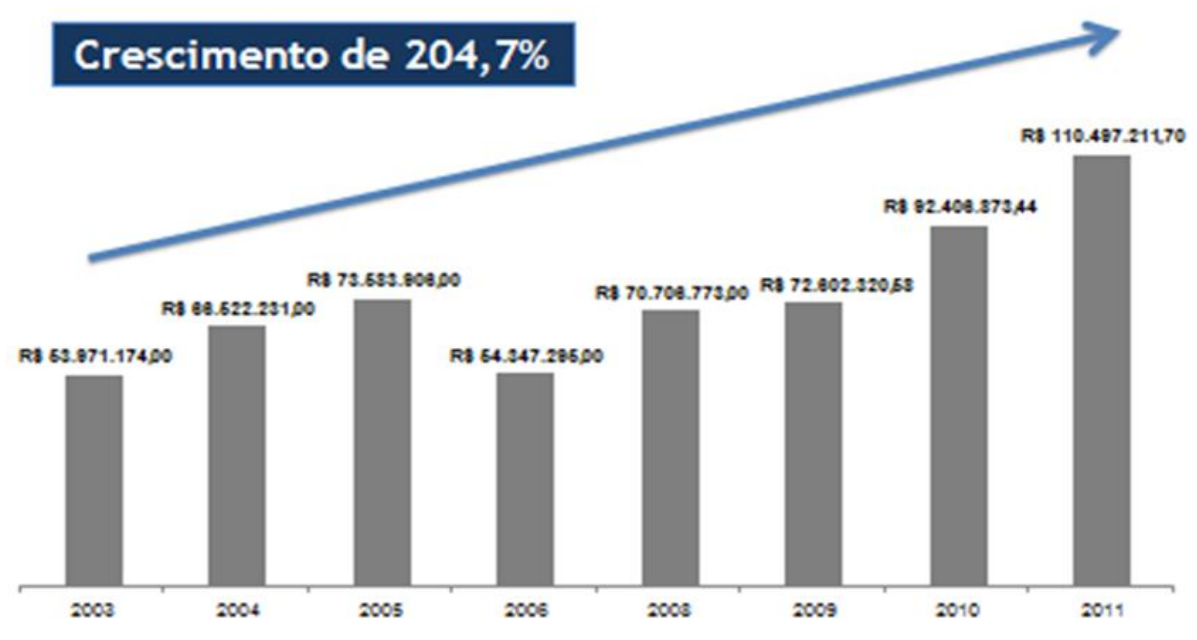

Gráfico 1. Total do investimento publicitário em TV aberta no Vale do Paraíba Fonte: Elaborado pelas autoras, com base em dados do IBOPE (2011).

O crescimento dos investimentos no meio televisivo, no período de 2003 a 2011, foi de $204,7 \%$. É importante destacar que todos os valores são preços de tabela dos veículos desconsiderando as negociações comerciais praticadas entre os clientes e as televisões. Com 
esses dados, conclui-se que o desenvolvimento da televisão interfere diretamente na indústria da comunicação, sendo fundamental para todo esse segmento de negócio e tendo o mesmo eco regional dos acontecimentos e das projeções nacionais.

\subsection{Caracterização da TV regional no Vale do Paraíba}

As variáveis que determinam a região considerada neste trabalho são delimitadas pelo processo midiático. O foco são as duas cidades que receberam as concessões públicas para instalação das sedes das emissoras regionais na mesorregião do Vale do Paraíba: São José dos Campos e Taubaté. Duas emissoras de televisão com características locais instaladas nas cidades acima citadas são: a Rede Bandeirantes Vale do Paraíba e a Rede Vanguarda.

Há também outras duas emissoras atuando comercialmente no mercado do Vale do Paraíba - a Rede Record e o SBT -, mas, como não possuem afiliadas locais, não fazem parte deste estudo.

As primeiras emissoras que se instalaram na região foram as que propuseram o desenvolvimento inicial da publicidade, proporcionando o crescimento do mercado publicitário regional, evidenciando a observação de José Marques de Melo sobre a comunicação como motor do desenvolvimento.

A TV Globo Vale do Paraíba começou sua atuação em 1988, em São José dos Campos, sendo a primeira emissora regional instalada no Vale do Paraíba. Em 2003, um grupo de empresários comprou a concessão e a emissora se tornou uma afiliada.

Logo na sequência, o mesmo grupo adquiriu mais uma concessão em Taubaté, e se formou a Rede Vanguarda, com sinal dividido entre as duas emissoras, conforme o atlas de cobertura de janeiro de 2010, da própria Rede Vanguarda. A cobertura do sinal da emissora em São José dos Campos compreende as seguintes cidades: Atibaia, Bragança Paulista, Caçapava, Campos do Jordão, Igaratá, Jacareí, Jambeiro, Joanópolis, Monteiro Lobato, Paraibuna, Piracaia, Santo Antonio do Pinhal, São Bento do Sapucaí, São José dos Campos, Vargem.

Já a cobertura da emissora de Taubaté atinge as seguintes cidades: Aparecida, Arapeí, Areias, Bananal, Cachoeira Paulista, Canas, Caraguatatuba, Cruzeiro, Cunha, Guaratinguetá, Ilha Bela, Lagoinha, Lavrinhas, Lorena, Natividade da Serra, Pindamonhangaba, Piquete, Potim, Queluz, Redenção da Serra, Roseira, São José do Barreiro, São Luiz do Paraitinga, São Sebastião, Silveiras, Taubaté, Tremembé, Ubatuba 
A Band Vale, inaugurada em 3 de setembro de 1996, é uma emissora própria da Rede Bandeirantes de Televisão, mas possui gestão administrativa e financeira regional. A cobertura de seu sinal compreende todo o Vale do Paraíba, a Serra da Mantiqueira e o Litoral Norte, totalizando 38 cidades com um único sinal.

Já o SBT possui, para a região do Vale do Paraíba, da Serra da Mantiqueira, do Litoral Norte de São Paulo e da região Bragantina, um sinal gerado via satélite originalmente partindo da capital paulista, somente com publicidade local, sem uma programação específica para a região.

A TV Record é gerada em Santos (SP), tendo sinal em toda a Baixada Santista; em 2009, passou a atingir também o Vale do Paraíba, mas cobrindo dois mercados, que não são sinérgicos em suas características, com o mesmo sinal.

A publicidade e a propaganda experimentaram um novo modelo de negócio com esse surgimento, ocasionado pela possibilidade tecnológica e que trouxe a instalação das TVs, proporcionando ao mercado publicitário regional a condição de fazer a propaganda televisiva que por anos foi inacessível ao empresário local. Antes da instalação das afiliadas, quem quisesse anunciar em televisão só conseguiria por meio do sinal vindo da capital paulista, com preços impraticáveis ao pequeno e médio empresário regional. Além disso, o foco da emissora com sede em São Paulo sempre foi, e continua sendo, empresas de atuação em todo o Estado. Já com a emissora regional, abre-se uma porta ao empresário do Vale do Paraíba, da Serra da Mantiqueira e do Litoral Norte para colocar seus produtos/serviços na maior vitrine eletrônica do país: a televisão.

O sinal regional de televisão chegou com preços compatíveis à sua área de cobertura, viabilizando a propaganda televisiva ao empresário local. A economia do Vale do Paraíba recebeu o incremento de novos anunciantes, e percebe-se um movimento publicitário impulsionado com as atuações das novas agências de propaganda, que motivam as produtoras de vídeo e fornecedores do segmento da comunicação, desenvolvendo toda uma cadeia produtiva em torno desse ramo publicitário.

Percebe-se, hoje, a necessidade cada vez mais premente de adequação da comunicação de produtos/serviços à realidade de cada mercado. Straubhaar (2007, p. 11) valida essa realidade que se vê hoje no mercado publicitário regional, ao desmembrar, em dez itens, o global do local. E um desses itens elucida a informação tratada acima:

A mídia local parece representar um nível de identidade e credibilidade na maioria das pessoas. Atualmente a mídia local continua mais ligada a jornais, revistas, músicas, rádios e internet, mas isso pode mudar com o 
barateamento das tecnologias, que faz com que a produção de TV seja cada vez mais viável.

No que diz respeito ao conteúdo das emissoras, percebe-se que a tendência nacional de programas que possam agradar a diversos segmentos da sociedade também em emissoras locais, que criam programas específicos e segmentados.

A necessidade de valorizar massas crescentes de capital em períodos de tempo cada vez mais curtos torna-se cada vez mais aguda, sob pena de não se realizar um volume de valor suficiente para revigorar o investimento produtivo. Para responder a essas dificuldades, o mundo empresarial tem apostado na criação de segmentos de mercado crescentemente especializados e individualizados como forma de elevar os níveis de consumo e a consequente renovação do estoque de mercadorias. A constante replicação dos desejos de consumo fomenta a efemeridade de modas, de padrões de consumo, de produtos e, consequentemente, de estilos de vida (AGUIAR, 2010, p. 181).

A televisão também segue essa tendência de segmentar, dentro das possibilidades do meio. É o que se vê nos conteúdos televisivos, em programas específicos para jovens, crianças, donas de casa, empresários, etc. Cada um desses segmentos está sendo contemplado no conteúdo das emissoras, em horários específicos, para atingir exatamente a quem se destina a informação. Tem-se, como exemplo, o jornalismo regional, focado em informar as notícias da região que impactam diretamente na vida de todos os moradores de seu raio de cobertura.

Silva (2006, p. 289) cita que a regionalização da TV é uma tendência mundial:

A regionalização da televisão já era prevista por muitos estudiosos da comunicação, como sendo um fenômeno da década de 90 no Brasil. Elas chegariam com as tevês a cabo e as comunitárias, tão comuns nos EUA. O público sente necessidade de obter notícias rápidas e precisas sobre sua região, não apenas através de jornais impressos locais.

A receptividade dos programas regionais dá sua resposta nos resultados de audiência. Pesquisa do IBOPE Media Workstation, de novembro de 2010, identificou que várias das maiores audiências da TV regional estão nos programas produzidos localmente e com assuntos focados no interesse da comunidade. Consequentemente, a busca do anunciante por esses programas é altamente concorrida, já que quanto maior a audiência, maior a visibilidade e o retorno ao cliente.

\subsection{Método}

A pesquisa caracteriza-se como exploratório-descritiva, de abordagem qualitativa, com coleta de dados por meio de entrevista semiestruturada. A amostra foi selecionada pelo critério de julgamento dos atores sociais participantes do processo de implantação das 
televisões regionais, na década de 1990, nas cidades de São José dos Campos e de Taubaté. Foram identificados profissionais das agências de propaganda e dos veículos de comunicação que atuam há mais de 15 anos na área ou que já estão fora do mercado, mas atuaram no passado, de forma intensa; os fornecedores, ou seja, as produtoras de áudio e vídeo; e, ainda, os anunciantes, que fazem propaganda há mais de 15 anos e que vivenciam, de forma prática e ativa, as transformações no mercado, totalizando onze entrevistas.

A pesquisa foi executada nas cidades de São José dos Campos e de Taubaté, que se constituem como as principais cidades do Vale do Paraíba. São também os principais municípios de atuação publicitária das emissoras de TV abordadas nesta pesquisa, até porque são nessas cidades que estão instaladas suas respectivas torres geradoras de transmissão do sinal regional.

\subsection{Resultados e discussão}

A partir das entrevistas realizadas, pode-se dizer que a televisão foi fator que impulsionou a estruturação do mercado publicitário de São José dos Campos e de Taubaté, por diversos aspectos:

- viabilizou a distribuição mais intensiva das mensagens publicitárias regionais, por ser um veículo de ampla cobertura e alcance, em relação às outras mídias anteriormente existentes na região;

- estimulou a organização do mercado, uma vez que o meio televisivo exige o cumprimento de determinados padrões de qualidade para veiculação das mensagens publicitárias, fomentando uma profissionalização maior das agências de propaganda;

- a perspectiva de crescimento e o cumprimento de padrões de qualidade exigiram a formação de uma mão de obra mais qualificada, o que se refletiu no aumento do número de instituições de ensino superior que ofertam o curso de Comunicação Social com habilitação em Publicidade e Propaganda;

- a inserção dos veículos de comunicação de grande porte estimula a necessidade dos processos de geração de dados sobre o cenário regional, tais como dados de audiência e perfil de consumidores, o que revela uma melhor organização e gera mais conhecimento do mercado.

Durante a pesquisa apresentada neste trabalho, verificou-se a quase unanimidade nas opiniões dadas pelos atores sociais entrevistados sobre o fato de que antes da implantação da televisão regional o mercado publicitário do Vale do Paraíba era pouco expressivo. "Existiam 
poucas opções de mídia de massa", lembra a entrevistada 1, anunciante que atua há 29 anos no varejo da região. "Tínhamos um mercado mais restrito, com poucas opções de mídias, apenas com rádios, jornais, revistas e outdoors para os empresários se comunicarem com seus clientes", acrescenta.

Os anunciantes, nesse período, eram basicamente de dois tipos: lojas de automóveis e construtoras ou imobiliárias, afirma o entrevistado 2, diretor de agência de propaganda que iniciou suas atividades em 1988 e que atua, até hoje, como uma das principais no Vale do Paraíba.

O entrevistado 3, diretor de agência já extinta, estabelecida em Taubaté em 1980, e que, apesar de não atuar na área da comunicação, atualmente, teve importante participação no processo publicitário regional, explica o seguinte:

Tive a oportunidade de acompanhar e participar ativamente da transformação do mercado publicitário do Vale do Paraíba. Nos anos 70 começa a proliferação das rádios FMs (Stéreo Vale. Piratininga, Aparecida, Difusora São José dos Campos, Itaipu Taubaté), já era necessário um trabalho de mídia, pois o mercado já começa o processo de segmentação com tantas emissoras de rádios instaladas e em instalação. $O$ jornal não era uma mídia muito habitual em função do custo e do pouco profissionalismo na estrutura comercial não respeitando as agências e os corretores.

Também foi possível identificar o baixo nível técnico e profissional do mercado de comunicação e a falta de um compromisso com a ética e com a normatização do setor que marcaram aquela época. Isso porque a Lei $\mathrm{n}^{\circ}$ 4680/65 determina o pagamento pelos veículos de comunicação de massa para as agências de propaganda referente ao comissionamento de $20 \%$ de toda a propaganda veiculada, e os veículos estabelecidos até então, no mercado, muitas vezes não respeitavam essa lei. Quando o entrevistado 3 fala sobre o "pouco profissionalismo na estrutura comercial não respeitando as agências e corretores", na verdade ele se refere ao descumprimento dessa lei, que normatizou, em 1957, a publicidade no país.

Com a implantação da $T V$ Globo - que, desde sua inauguração, respeitou rigorosamente as regras estabelecidas pela citada lei -, o meio publicitário como um todo acabou sendo influenciado positivamente. O entrevistado 4, que atuava, na ocasião da entrevista, como diretor de TV universitária em São José dos Campos, mas que na oportunidade da implantação da TV regional atuava como proprietário de uma produtora de vídeos publicitários, afirma:

Foi uma grande revolução, na época surgiram dezenas de agentes publicitários vendendo mídia TV, mas sem nenhum tipo de planejamento. Todo o mercado queria vender mídia TV. Afinal o Bônus de Veiculação de $20 \%$ era maior que qualquer outra fonte de renda no mercado. As agências eram poucas e mal preparadas para a área de TV. 
Segundo o entrevistado 5, publicitário e proprietário de agência, "a coisa começou a tomar um rumo um pouco mais profissional com a chegada das emissoras, e de forma mais emblemática com a chegada da toda poderosa Rede Globo". E ele ainda complementa: "Me lembro que a chegada da Rede Globo coincide com a chegada do shopping. Investidores comuns, pois os donos do shopping tinham ligação com a família de Roberto Marinho. Estes dois eventos fazem a linha divisória do crescimento publicitário e do desenvolvimento comercial de São José dos Campos e da região".

A implantação da televisão também determina a estruturação das agências, conforme afirma o entrevistado 6, diretor e sócio de representativa agência de propaganda: "o mercado era inexpressivo pela falta de veículos de massa, que permitissem a montagem de uma agência estruturada". Além disso, afirma também "o pagamento do comissionamento é muitas vezes uma importante fonte de receita para a agência se estruturar."

A entrevistada 7, atendimento de agência de São José dos Campos, comenta as características do mercado publicitário antes da implantação da TV no Vale do Paraíba: "havia, na época, algumas agências que se esforçavam para fazer um trabalho mais profissional, mas a falta de veículos éticos, que remunerassem as agências, inviabilizava a continuidade dessas empresas". Ela ainda faz uma avaliação sobre o início das agências de propaganda, dizendo que "a maioria das agências começaram apenas como agenciadores de mídia, sem uma preocupação de oferecer outros serviços aos clientes, por outro lado, algumas poucas, mais profissionais, contribuíram de forma decisiva para o desenvolvimento do mercado".

Os meios de comunicação, em especial a televisão, foram se revitalizando durante os anos, para se adequar à demanda do mercado publicitário regional. Percebe-se, também, que a constante busca de uma comunicação mais próxima aos interesses da população local, a identidade e a sinergia com a população levam as emissoras a conquistar uma reputação de sua marca com alta credibilidade, proporcionando mais resultado aos anuciantes.

Para a entrevistada 8, assessora de marketing político, a chegada da TV Globo Vale do Paraíba

foi uma grande mudança, pois possibilitou regionalizar a comunicação. Anunciantes que antes não podiam utilizar o meio TV, por ser muito caro e abranger uma região muito maior do que suas áreas de atuação, passaram a contar com esse poderoso veículo, por outro lado, as agências passaram a especializar-se mais, tanto em planejamento de mídia, quanto em produção para TV, iniciando um processo de profissionalização e amadurecimento do mercado. 
É senso comum, entre praticamente todos os entrevistados, a questão da viabilidade econômica. A implantação das televisões regionais proporcionou para os anunciantes o acesso ao meio televisão, para divulgar seus produtos e serviços. Houve um fenômeno interessante, como diz a entrevistada 7: "Todo mundo queria anunciar na TV, a novidade da televisão regional, fez com que empresários locais pudessem colocar seus produtos na televisão".

Diretor de agência, o entrevistado 9 afirma: "O surgimento da TV regional possibilitou o acesso à mídia de massa com valores mais acessíveis aos anunciantes".

A implantação da TV revelou aspectos positivos, que foram abordados pelos atores sociais entrevistados nesta pesquisa. O entrevistado 3, por exemplo, afirma, categoricamente: "a chegada da Rede Globo trouxe novos ares para o mercado regional com uma conduta ética e de respeito às agências regionais". O entrevistado 6 também afirma que a chegada da televisão ao Vale de Paraíba "foi a primeira oportunidade de anunciantes de atuação regional utilizar um meio de maior eficácia e o mercado publicitário então começou a se organizar para atender a essa e outras demandas".

Com isso, pode-se afirmar que o mercado publicitário começa a se organizar, e a televisão, de certa forma, determina as regras para todo o meio publicitário, por meio de normas e condutas a serem estabelecidas a partir desse momento. Acredita-se que os outros meios, como rádios, jornais e revistas, acabam balizando suas normativas a partir da televisão, como exemplifica o entrevistado 4: "O mercado era basicamente voltado ao meio impresso, jornal e mídias alternativas".

As agências realizavam um trabalho limitado antes das TVs regionais, mas, com o surgimento delas, a profissionalização foi condição de sobrevivência, segundo o entrevistado 6, que afirma: "Com a presença de um meio de maior penetração junto aos consumidores, as agências tiveram que se estruturar e criar condições técnicas e profissionais para atender os anunciantes".

Os anunciantes também percebem a importância da comunicação televisiva para o seu negócio. A entrevistada 1 afirma que

o impacto foi grande, as empresas perceberam que a força da TV possibilita um rápido retorno na comunicação. A opção em escolher a divulgação na TV ao invés de outras mídias foi rapidamente percebida pela nossa empresa, que começou a anunciar na TV desde o início da emissora na região e sempre que temos campanhas colocamos nossos filmes na televisão até os dias de hoje.

Ela também afirma que utiliza a mídia televisiva para gerar um impacto imediato no consumidor, principalmente em datas comemorativas, como Dia das Mães, Dia dos Namorados, Dia dos Pais e Natal: "Essa é uma estratégia que comunica muitas pessoas de 
uma vez só e também cria mais sinergia com o público-alvo, além de se diferenciar da concorrência se posicionando no mercado".

Identifica-se, por outro lado, certo status causado pela televisão, que exerce fascínio sobre as pessoas, conforme afirma o entrevistado 10, sócio diretor de produtora de vídeos publicitários, que em 1988 trabalhava na Rede Globo. Ele conta: "Era importante a marca estar no ar, antes de pensar na campanha como retorno, o anunciante entendia toda essa ação como status para o seu nome". O entrevistado 4 confirma esse ponto de vista, assegurando: "Acredito que, para muitos anunciantes, a mídia TV era o sonho, mesmo que não fosse adequado estar na TV era símbolo de status para a empresa".

Aos poucos, o anunciante foi sentindo o incrível resultado em seu negócio, proporcionado pela televisão, e, assim, acreditando cada dia mais no veículo. O entrevistado 3 afirma que os anunciantes tiveram a oportunidade de experimentar um veículo que possui rápida resposta ao investimento publicitário.

Mas para a marca de um cliente estar no ar e os anunciantes experimentarem televisão, é necessário o filme para ser veiculado, filme este com qualidade técnica e com padrão de exibição em televisão. Como recorda o entrevistado 11, diretor e apresentador de programa de TV, "com a chegada da Rede Globo foram montadas as primeiras produtoras profissionais".

O entrevistado 9 conta, ainda, que "não existiam produtoras em operação na época e acredito que as produtoras que mais se beneficiaram com a implantação da TV regional, até mais que as agências, pois as agências continuariam a operar se a TV regional não existisse, ao passo que as produtoras não".

A Rede Globo, quando se instalou em São José dos Campos, montou uma produtora de vídeo interna, com o objetivo de fomentar o mercado, ensinando e desenvolvendo a cultura de televisão não só para os anunciantes, mas também para todos os participantes do processo publicitário, bem como para implantar o padrão global de imagem.

O entrevistado 2 conta que havia, na época, apenas produtoras que filmavam casamentos; por isso mesmo, precisaram adquirir equipamentos e um nível técnico melhor. O divisor de águas, na opinião dele, foi o momento em que a Rede Globo parou de produzir comerciais e as produtoras tiveram realmente que se adequar ao padrão global, produzindo materiais com qualidade técnica para televisão. A entrevistada 7 corrobora, dizendo:

As produtoras tiveram sua grande oportunidade de crescer. Na verdade, a chegada das TVs gerou esse novo negócio para a região, que antes não existia. Quando a TV Globo chegou, a empresa instalou uma produtora de vídeo interna, pois ainda não existiam produtoras com equipamentos compatíveis à transmissão de televisão. E com isso, as pequenas produtoras que atuavam na época e faziam gravação de festas, casamentos e outras 
atividades foram se aperfeiçoando com equipamentos e profissionais técnicos para atuarem no mercado publicitário. Surgiram também produtoras focadas em trabalhos para a televisão. Depois de certo tempo a globo pode focar em seu core-business e fechou a produtora interna, afinal o mercado já tinha outras possibilidades de viabilizar seus filmes publicitários para exibir na TV.

É também do entrevistado 9 a afirmação de que as agências tiveram que "aprender a linguagem e a passar a mensagem eficaz em um tempo reduzido". Afinal, o padrão de propaganda em TV é o comercial de 30 ou 15 segundos. Por isso, faz-se necessário o alto poder de síntese com coerência para comunicar a informação desejada, o que é fundamental para que a campanha publicitária possa atingir seus objetivos. O entrevistado2, por sua vez, entende que "o mercado foi aprendendo a anunciar aos poucos, a qualidade e a adequação das mensagens foram melhorando, os anunciantes foram ficando mais conscientes e depois de amargar erros do passado, passou a colher bons frutos do investimento em propaganda".

A necessidade de produção de qualidade não é só técnica, mas também criativa e publicitária; em outras palavras, é condição primordial para que os anunciantes tivessem o retorno de vendas e institucional esperado. Algumas agências e produtoras nasceram e, pouco tempo depois, fecharam suas portas, pois sem qualidade não conseguiram se estabelecer de forma profissional no mercado. Isso ainda acontece nos dias atuais, pois a concorrência cada vez maior e a $\mathrm{O}$ entrevistado 2 concorda:

As agências foram se profissionalizando 'na marra'. A necessidade de criar e produzir comerciais de TV bons e baratos começou a ser um desafio cada vez maior. Muitas agências fracassaram e morreram no meio desse processo. Até hoje algumas continuam nascendo e morrendo. É preciso muito talento para conseguir entregar bons comerciais para o anunciante e o consumidor com verbas pequenas e fazer com que essas mensagens se destaquem positivamente dentro de uma programação de nível cada vez mais elevado, como é o da TV e das propagandas brasileiras.

A chegada da TV Band Vale determina o fim do monopólio da televisão regional. A Globo não está mais sozinha: naquele momento, o mercado ganha uma segunda opção em mídia televisiva. Ana Lúcia Junqueira defende que a "concorrência é fator determinante para o desenvolvimento de qualquer mercado".

A TV Band Vale trouxe, consigo, um desafio para a Rede Globo, que já estava estabelecida, proporcionando uma saudável concorrência. Para o anunciante e para o telespectador, contar com mais uma televisão regional representa poder de escolha. A entrevistada 8 lembra que a TV Band Vale abriu a possibilidade de veicular produção independentes, por meio da venda de espaços, formato inédito até então, abordando questões regionais que são relevantes a toda a comunidade. 
O entrevistado 6 afirma que a implantação da TV Band Vale representou "a consolidação do meio junto ao mercado e aos anunciantes". A entrevistada 1, por sua vez, acredita que "a vinda da Band foi positiva impactando o mercado e abrindo mais opções para o empresariado local atingir outros públicos". E o entrevistado 3 reforça a ideia: "Livrou o mercado da exclusividade da Rede Globo, ampliando ainda mais o desenvolvimento do negócio da comunicação no Vale do Paraíba”.

Com uma política comercial pautada na consultoria ao anunciante e na orientação das agências de propaganda sobre como tirar maior proveito da mídia televisiva, a TV Band Vale chegou oferecendo, ao mercado regional, um modelo de atuação diferenciado, segundo o entrevistado 2: "O atendimento das emissoras deixou de ser um simples apresentador de tabelas de preços". Com duas opções de TV regional, o profissional do veículo precisa se aperfeiçoar; por isso mesmo, entrevistado 2 ainda considera que o profissional de mídia passou a ser relevante dentro da agência para avaliar com mais critério as possibilidades de mídia para os clientes e anunciantes. O entrevistado 3, para completar, diz: "A TV Band Vale sempre teve uma política de relacionamento mais próximo da realidade local".

Também há de se levar em conta a implantação dos escritórios comerciais regionais do SBT e da Record, que, apesar de não serem o foco deste trabalho, não podem ser ignorados. Efetivamente, não se tratam de emissoras com concessões públicas nessa região; sendo assim, não são consideradas locais, conforme os parâmetros estabelecidos para a realização da pesquisa. Porém, apesar de o SBT ter seu sinal oriundo de São Paulo, e a Record, da Baixada Santista, eles possuem, no Vale do Paraíba, escritórios comerciais para venderem espaços publicitários. Com isso, também contribuem e são relevantes para todo o processo publicitário regional, com mais possibilidade de opções aos anunciantes e telespectadores.

Todo esse processo amplia ainda mais o desenvolvimento da indústria da comunicação no Vale do Paraíba, conforme a entrevistada 8 afirma:

Os escritórios comerciais dessas emissoras têm um impacto extremamente positivo no mercado publicitário, uma vez que é oferecido ao anunciante uma combinação variada de possibilidades de veiculação, segmentando-se os públicos, já para as agências, essa variedade possibilita planos de mídias mais elaborados, e, claro a concorrência sempre acaba favorecendo o aquecimento do mercado.

A Figura 1 destaca os principais fatos que marcaram o desenvolvimento do mercado publicitário regional, evidenciando a chegada das emissoras de televisão, o início das produtoras de vídeos publicitários para televisão, a instalação da principal agência de 
propaganda na região - que atua até os dias atuais - e o início dos cursos de graduação e de pós-graduação.

Verifica-se que o movimento convergente entre as instituições de ensino e o mercado se fortaleceu com a instalação das redes de TV regionais.
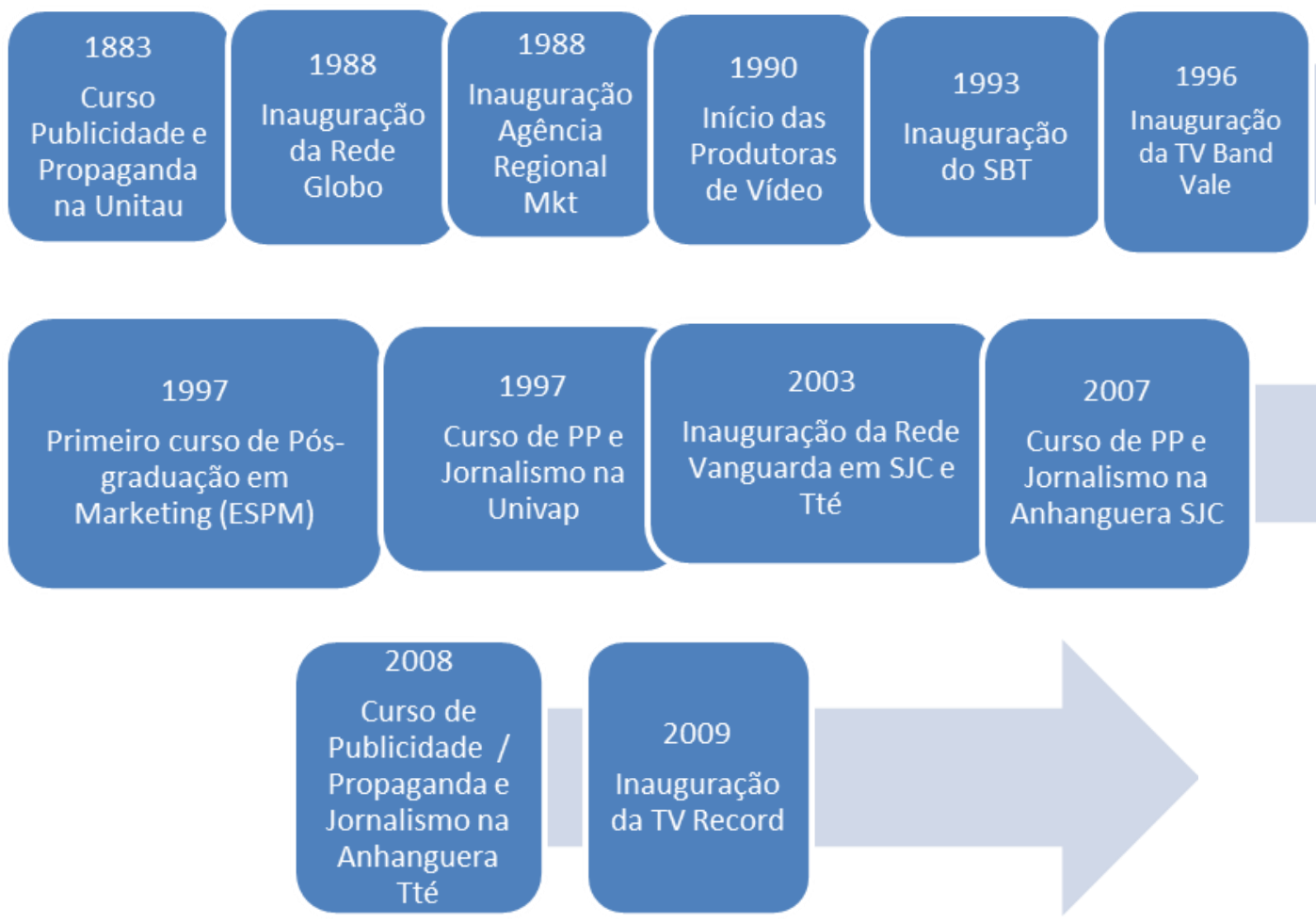

Figura 1. Linha do tempo do processo publicitário na região do Vale do Paraíba Fonte: Elaboração das autoras a partir dos dados da pesquisa, 2011.

\section{CONSIDERAÇÕES}

A mesorregião do Vale do Paraíba abriga um número de agências de comunicação bastante representativo, das quais 37 são filiadas ao CENP (CENP, 2011). No entanto, há uma nítida concentração das agências certificadas no município de São José dos Campos, município que sediou a primeira emissora de TV regional. O segundo município em número de agências certificadas é Taubaté, que, não por coincidência, também sedia emissoras regionais. Nota-se uma estreita relação entre a prevalência das emissoras de televisão regionais e a maturidade do mercado publicitário.

É possível inferir que esse cenário foi se configurando desde o processo de industrialização ocorrido na região, a partir da década de 1950, que a tornou potencialmente atrativa pela necessidade de mão de obra gerada pelas novas indústrias, fator que estimulou os investimentos na região. E outro fator que também revela o potencial do mercado local foi a 
PROGRAMA DE PÓS-GRADUAÇÃO EM COMUNICAÇÃO DA UNIVERSIDADE FEDERAL DE SANTA MARIA

instalação das emissoras de TV, que impulsionou a estruturação do mercado publicitário regional por diversos aspectos.

Destaca-se que, nesta pesquisa, o objetivo geral foi caracterizar o mercado publicitário a partir da implantação da televisão aberta regional em São José dos Campos e Taubaté. Tal meta foi alcançada, posto que os atores sociais que atuavam no meio publicitário, quando da instalação da Rede Globo no Vale do Paraíba e da TV Band Vale, fizeram suas análises sobre o mercado a partir da implantação das referidas emissoras.

Pelo levantamento realizado, observa-se que o mercado publicitário realmente se desenvolveu na região do Vale do Paraíba, com a chegada da televisão regional. As TVs proporcionaram o crescimento em várias áreas da economia, abrindo as portas da vitrine eletrônica para o varejo local, com valores compatíveis ao comerciante regional, que pôde colocar sua marca na televisão e divulgar seus produtos e serviços. Em decorrência desse fato, toda uma cadeia produtiva da indústria da comunicação se estabeleceu em torno dessa nova realidade. Várias vertentes da economia regional foram impactadas. A saber:

- as agências de propaganda obrigatoriamente tiveram de se estruturar para atender às exigências impostas pelo padrão televisivo de atuação publicitária;

- novos postos de trabalho foram necessários, com especificidades voltadas ao meio publicitário;

- o desenvolvimento do meio televisão proporcionou o aumento dos anunciantes, e a verba publicitária é maior a cada ano, movimentando a economia da região;

- os profissionais precisam se preparar e se aperfeiçoar; com isso, as instituições de ensino se motivaram a atuar mais fortemente na área da comunicação, ofertando cursos regulares e de extensão para os profissionais;

- a concorrência entre as emissoras trouxe e traz benefícios aos anunciantes que buscam a televisão para divulgar seus produtos e serviços.

Concluiu-se, pela pesquisa, como tendência nacional, a regionalização cada vez maior da comunicação nos mercados brasileiros. O anunciante tem que se comunicar localmente, e busca desenvolver uma linguagem que tenha adequação com o mercado que deseja atingir. Lembra Sen (2000, p. 51): “a estreita relação que existe entre o desenvolvimento de uma região e o acesso à informação".

Pode-se afirmar que a informação publicitária, difundia por meio da televisão, propõe o desenvolvimento regional, e as várias facetas da economia que se entrelaçam nesse processo de estruturação regional são fortemente impactadas em busca da profissionalização. 
Rett (2004, p. 8) sintetiza, de forma clara, o desenvolvimento regional da TV, com vistas ao anunciante e aos profissionais da área, bem como traça um pequeno cenário do futuro da programação regional frente à nacional:

\begin{abstract}
A regionalização vem sendo considerada uma alternativa viável de fortalecimento da TV aberta. Dando espaço para a expressão da cultura regional, das peculiaridades de cada cidade, das suas festas, da sua religiosidade, a TV reforça sua identidade e credibilidade e é recompensada em forma de audiência, o que se reflete na atração de anunciantes e, conseqüentemente, no desenvolvimento do mercado local como um todo. Abre-se espaço para a atuação de editores, jornalistas, técnicos, engenheiros, publicitários, administradores, enfim, muitos profissionais que sobrevivem nesse mercado, e também para as universidades que têm que habilitar seus alunos para as diversas funções na área de comunicação. A TV Regional tende a ocupar um espaço maior nas redes, investir em tecnologia e criar alternativas de comunicação que reforcem sua identidade, valorizando e divulgando o que sua região tem de melhor.
\end{abstract}

Verifica-se que a vocação da televisão regional pode ser definida como um fator determinante para alavancar a economia e para proporcionar o desenvolvimento regional. Como diz Correa (2003, p. 96),

a vocação final de uma emissora de TV efetivamente integrada à comunidade é fazer jornalismo e programação local, alavancar a economia local por meio da publicidade, apoiar os eventos e iniciativas da região e, acima de tudo, colocar as pessoas da região na tela da TV.

Verifica-se, também, que esse assunto tem desdobramentos futuros que poderão ser estudados. Sugere-se, assim, um acompanhamento constante desse processo de desenvolvimento.

\title{
REFERÊNCIAS
}

AGUIAR, João Valente. Tempo social. Revista de Sociologia da USP, São Paulo, v. 22, n. 1, 2010.

ANGELO, Augusto de. A longa jornada da institucionalização. In: CASTELO BRANCO, Renato; MATENSEN, Rodolfo Lima; REIS, Fernando (Orgs.). História da propaganda no Brasil. São Paulo: T. A. Queiroz, 1990.

CARNIELLO, Monica Franchi. Mercado regional. In: Enciclopédia Intercom de Comunicação. São Paulo: Intercom, 2010. p. 809-810.

Propaganda regional. In: Enciclopédia Intercom de Comunicação. São Paulo: Intercom, 2010. p. 975-976.

CENP. Disponível em: 〈http://www.cenp.com.br>. Acesso em: 06 mar. 2011. 
PROGRAMA DE PÓS-GRADUAÇÃO EM COMUNICAÇÃO DA UNIVERSIDADE FEDERAL DE SANTA MARIA

CORREA, Eduardo. Como uma emissora de TV pode ajudar uma comunidade a crescer.

Mercado Global, Rio de Janeiro, n. 113, p. 96, $3^{\circ}$ trim. 2003.

DONOS DA MÍDIA. Disponível em: <http://www.donosdamidia.com.br>. Acesso em: 7 set. 2011.

IBOPE. Disponível em: <http://www.ibope.com.br/calandraWeb/servlet/Calandra Redirect?temp=0\&proj=PortalIBOPE\&pub=T\&db=caldb>. Acesso 10 jun. 2011.

LIMEIRA, Tania Maria Vidigal. E-marketing: o marketing na internet com casos brasileiros. São Paulo: Saraiva, 2007.

MELO, José Marques de. Comunicação e desenvolvimento: por um conceito midiático de região. In: MARQUES DE MELO, José; SOUSA, Cidoval Morais de; GOBBI, Maria Cristina (Orgs.). Regionalização midiática: estudos sobre comunicação e desenvolvimento regional. Rio de Janeiro: Sotese, 2006. p. 13-35.

NOVAES, Adauto. Anos 70: ainda sob a tempestade. Rio de Janeiro: SENAC Rio, 2005.

PERUZZO, Cicilia M. Krohling. Mídia local e suas interfaces com a mídia comunitária. In: CONGRESSO BRASILEIRO DE CIÊNCIAS DA COMUNICAÇÃO, 26., Belo Horizonte, 2003. Anais eletrônicos... São Paulo: Intercom, 2003.

PROJETO INTERMEIOS. Relatório 2009. São Paulo: Meio \& Mensagem, 2010.

Disponível em: <http://www.projetointermeios.com.br〉. Acesso em: 6 mar. 2011.

REIS, Fernando. São Paulo e Rio: a longa caminhada. In: CASTELO BRANCO, Renato; MATENSEN, Rodolfo Lima; REIS, Fernando (Orgs.). História da propaganda no Brasil. São Paulo: T. A. Queiroz, 1990.

RETT, Lucimara. TV Regional, a rede transformando o mercado local. In: COLÓQUIO INTERNACIONAL SOBRE A ESCOLA LATINO-AMERICANA DE COMUNICAÇÃO, 8., São Bernardo do Campo, 2004. Anais eletrônicos... São Bernardo do Campo: Cátedra Unesco/Metodista de Comunicação para o Desenvolvimento Regional, 2004.

SEN, Amartya. Desenvolvimento como liberdade. São Paulo: Companhia das Letras, 2000.

SCHRAM, W. Comunicação de massa e desenvolvimento. Rio de Janeiro: Bloch, 1970.

SILVA, Robson Bastos da. Limites e possibilidades da TV regional. In: MARQUES DE MELO, José; SOUSA, Cidoval Morais de; GOBBI, Maria Cristina (Orgs.). Regionalização midiática: estudos sobre comunicação e desenvolvimento regional. Rio de Janeiro: Sotese, 2006. p. 289-295.

STRAUBHAAR, Joseph. Caminhos glocais para a televisão. Intercom - Revista Brasileira de Ciências da Comunicação, São Paulo, v. 30, n. 2, p. 181-191, jul./dez. 2007. 
PROGRAMA DE PÓS-GRADUAÇÃO EM COMUNICAÇÃO DA UNIVERSIDADE FEDERAL DE SANTA MARIA

Original recebido em: 05/11/2012

Aceito para publicação em: 25/09/2014

Giselle da Cunha Estefano Toledo Mestre em Desenvolvimento Regional pela Universidade de Taubaté - SP, Brasil. Diretora Comercial da Rede Bandeirantes do Vale do Paraíba.

Monica Franchi Carniello

Doutora em Comunicação e Semiótica pela PUCSP, com pós-doutorado pela UMESP. Professora e pesquisadora do Mestrado em Gestão e Desenvolvimento Regional da Universidade de Taubaté - SP, Brasil. 